\title{
Infection associated hemophagocytic lymphohistiocytosis. An institutional experience
}

\author{
Kavitha Kanjirakkattumana Parameswaran', Shehla Basheer Kollathodi ${ }^{2}$ \\ ${ }^{1}$ Senior Consultant, ${ }^{2}$ Junior Consultant, Department of Pathology, Aster MIMS Hospital Kozhikode, Kerala, India
}

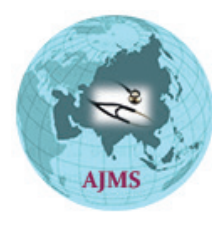

A B S TR A C T

\begin{abstract}
Background: Hemophagocytic lymphohistiocytosis is an uncommon yet potentially lifethreatening disorder. Even though an early recognition of this condition is critical, the diagnosis is often delayed due to a lack of awareness, as well as lack of specific clinical and laboratory features. There is no gold standard for confirmation of a suspected case of HLH. Aims and Objectives: In this article, we share our experience in infection-associated HLH, in the light of a thorough literature search. Materials and Methods: We analyzed the clinicopathological features of 11 consecutive patients who were admitted to our hospital from July 2017 to January 2019 with a diagnosis of HLH. Bone marrow material was collected from all but one case, and the marrow aspirate and biopsy were studied in detail. Results: There were 9 adult and 2 pediatric patients with HLH. The infections associated with HLH were Dengue fever, Influenza B, and Adenovirus infection. One child had features of severe sepsis, but the causative agent was not identified. Eight out of 11 patients succumbed to the illness. Conclusion: This study highlights the high mortality rate related to infection associated HLH. Timely diagnosis and early aggressive treatment can improve the clinical outcome of this otherwise potentially fatal condition. Physicians should have a high index of suspicion when patients develop prolonged fever associated with cytopenia and multi-organ involvement.
\end{abstract}

Access this article online Website:

http://nepjol.info/index.php/AJMS DOI: /10.3126/ajms.v10i4.23832 E-ISSN: 2091-0576 P-ISSN: 2467-9100

Key words: Hemophagocytosis; Lymphohistiocytosis; Dengue

\section{INTRODUCTION}

Hemophagocytic lymphohistiocytosis (HLH) is an aggressive and fatal disease, characterized by dysregulation of natural killer T lymphocyte function, as well as activation and proliferation of histiocytes with uncontrolled haemophagocytosis and cytokine production. ${ }^{1}$ HLH was first described 70 years ago. ${ }^{2}$ Later, virus-associated HLH was described by Risdal et al. ${ }^{3}$ HLH can be primary or secondary and both share a common feature of high mortality unless appropriate treatment is given. ${ }^{4}$ Primary or familial HLH is an autosomal recessive genetic disorder whereas secondary HLH occurs secondary to other diseases like infections, malignancies, etc. Infections can trigger both primary and secondary HLH.

The Histiocytic society has put forward the HLH-1994 criteria for diagnosis of HLH, which was later updated to HLH-2004 criteria. ${ }^{5,6}$ Even though the criteria was put forward for the diagnosis of HLH in pediatric patients, the same is mostly used for adults also. According to the criteria, either a molecular diagnosis or $5 / 8$ of the following parameters should be present to arrive at a diagnosis of HLH. The parameters include fever, splenomegaly, cytopenia, hyper-ferritinemia, hypertriglyceridemia and/or hypofibrinogenemia, hemophagocytosis, decreased natural killer (NK) cell activity and increased soluble interleukin-2 receptor (sIL2r) level. (Table 1).

\section{MATERIALS AND METHODS}

The study included patients who were admitted to our hospital with a diagnosis of HLH, during the period of July 2017 to January 2019. Details regarding clinical 
presentation, associated conditions, laboratory findings, and clinical outcome were collected from the medical records. Bone marrow aspiration and biopsy slides were evaluated in detail. Bone marrow aspiration smears were stained with Giemsa Leishman cocktail stain. Bone marrow biopsy cores were fixed in Bouin's fluid, and the sections were stained with hematoxylin and eosin stain. A thorough search for hemophagocytic cells (HPC) was done examining the entire marrow aspirate smear and biopsy sections.

\section{RESULTS}

A total of 11 infection associated HLH cases were there, of which 7 patients were males and 4 were females. There were 2 children and 9 adults. Presenting symptoms included fever (100\%), bleeding (45\%), abdominal pain and vomiting $(36 \%)$, cough (36\%), loose stools (27\%), headache (18\%) and seizure $(11 \%)$. The average duration of fever was 14 days. Clinical and laboratory parameters are summarized in table 2 .

Underlying infection was proven in all cases but one. The most common infection was dengue, in 8 patients, followed by influenza B and Adenovirus in one patient each. The infections were confirmed by positive serology tests. The underlying causative agent was not identified in one patient but features of severe sepsis were evident from the clinical and laboratory parameters. All the patients had a very high ferritin level with a minimum value of $39000 \mathrm{ng} / \mathrm{ml}$.

Bone marrow material was available for study in 10 out of 11 cases. Histiocytes which have engulfed intact erythrocytes, erythroid precursors, lymphocytes, neutrophils,

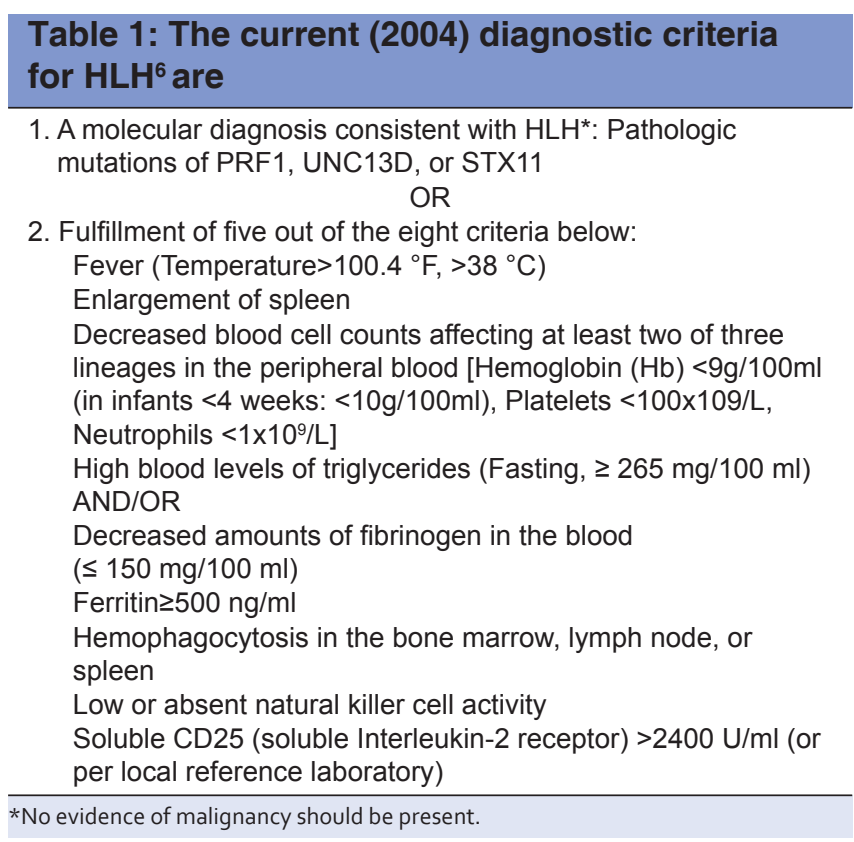

granulocyte precursors or plasma cells were considered as hemophagocytic cells (HPC). Hemophagocytic cells were demonstrated in all the 10 bone marrow aspirates (Figure 1a) and an average of 12 HPCs were noted in the smears. Marrow was hyper-cellular in 8 cases. Dyserythropoietic features like megaloblastoid change, binucleation, nuclear budding, etc., were evident in 5 cases of HLH, all of which were associated with dengue fever (Figure 1b). Unlike as in bone marrow aspirate, identifying HPCs in bone marrow biopsy was found to be difficult.

Even though not mentioned in the criteria, we looked into parameters like liver enzymes, serum lactate dehydrogenase (LDH) and activated partial thromboplastin time (APTT). We found a rise in liver enzymes, serum LDH and prolongation of APTT in $90 \%$ of the patients.

Immunosuppression by means of intravenous steroids was given in 5 patients, and 1 patient was given intravenous immunoglobulin (IVIG). Others received supportive care. Eight out of 11 patients succumbed to the disease. The causes of death were shock in 4 patients, cardiac arrest in 2 patients, and acute respiratory distress syndrome in 2 patients. Those who survived were followed up with tapering doses of steroid and their clinical condition improved.

\section{DISCUSSION}

HLH is a potentially fatal hyperinflammatory condition characterized by uncontrolled but ineffective immune function. Infection associated HLH is an important entity especially in tropics where infectious diseases are rampant and still pose a major threat. Epstein-Barr virus infection is one of the most common triggers for HLH. ${ }^{3,7}$ Other viral infections associated with HLH include hepatitis, adenovirus infection, measles, mumps, dengue, influenza etc. ${ }^{8-14}$ All though HLH is triggered mostly by Herpes family of viruses, in our study it was mainly associated with dengue fever followed by adenovirus and influenza $B$ virus infection. Only around 30 cases of adult dengue-associated HLH cases have been described in the literature so far. ${ }^{12}$ Even though HLH is more common among children, it can affect any age group, constituting a medical emergency, and there is no sex predilection. ${ }^{1}$

For adult HLH, no specific diagnostic criteria are established and so, the HLH-2004 pediatric diagnostic criteria are used for adults also. Even though the exact pathogenesis is not known, it is thought that HLH is due to an impairment in the function of cytotoxic $\mathrm{T}$ lymphocytes and NK cells. ${ }^{15}$ earlier it was thought that HLH is seen in immune-compromised patients, but later it became evident that it can affect immune competent patients as well. The 


\begin{tabular}{|c|c|c|c|c|c|c|c|c|c|c|}
\hline S.No. & $\begin{array}{l}\text { Agel } \\
\text { sex }\end{array}$ & $\begin{array}{l}\text { Associated } \\
\text { Infection }\end{array}$ & HSM & Cytopenia & $\begin{array}{l}\text { Prolonged } \\
\text { APTT }\end{array}$ & $\begin{array}{l}\text { High } \\
\text { Transaminase }\end{array}$ & Ferritin & $\begin{array}{l}\text { High } \\
\text { TGL }\end{array}$ & $\begin{array}{l}\text { BM } \\
\text { evidence } \\
\text { of HLH }\end{array}$ & Outcome \\
\hline 1 & $25 / F$ & Dengue & + & Bicytopenia & + & + & $>40000$ & + & + & $\mathrm{D}$ \\
\hline 2 & $52 / \mathrm{m}$ & Dengue & + & Bicytopenia & + & + & $>40000$ & - & + & $\mathrm{D}$ \\
\hline 3 & $48 / F$ & Dengue & - & Bicytopenia & + & + & $>40000$ & + & + & $\mathrm{D}$ \\
\hline 4 & $74 / \mathrm{M}$ & Dengue & + & Bicytopenia & + & + & 39500 & - & + & $D$ \\
\hline 5 & $48 / F$ & Dengue & + & Bicytopenia & + & + & $>40000$ & + & + & L \\
\hline 6 & $74 / \mathrm{M}$ & Dengue & - & Thrombocytopenia & + & + & $>40000$ & + & + & $\mathrm{D}$ \\
\hline 7 & $35 / M$ & Dengue & - & Bicytopenia & + & + & $>40000$ & + & + & $\mathrm{L}$ \\
\hline 8 & $58 / \mathrm{M}$ & Dengue & - & Anemia & + & + & $>40000$ & + & $\begin{array}{l}\text { No } \\
\text { marrow }\end{array}$ & $\mathrm{D}$ \\
\hline 9 & $4 / f$ & Unknown & + & Pancytopenia & + & + & $>40000$ & + & + & D \\
\hline 10 & 29/M & Influenza B & - & Anemia & - & + & $>40000$ & + & + & L \\
\hline 11 & $3 / \mathrm{M}$ & Adenovirus & + & Anemia & + & + & 39000 & - & + & $\mathrm{D}$ \\
\hline
\end{tabular}

Key: HSM-Hepatosplenomegaly, APTT-Activated partial thromboplastin time, TGL-Triglyceride, BM-Bone marrow, D-Died, L-Living

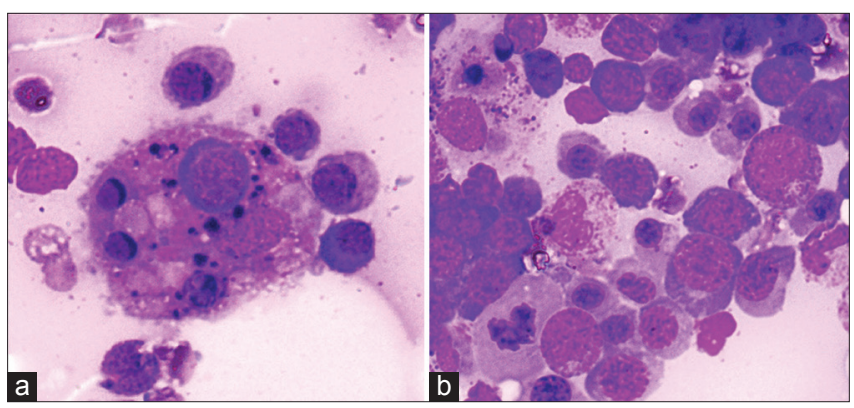

Figure 1: a) Bone marrow aspirate showing a hemophagocyte engulfing erythroid precursors and lymphocytes. b) Bone marrow aspirate showing erythroid hyperplasia and dyserythropoiesis. (GiemsaLeishman stain, 100x Oil).

true incidence of HLH is not known as it mostly remains underdiagnosed and as it is associated with a wide spectrum of clinical features. In one retrospective study in Sweden, the incidence was reported as $1.2 / 1,000,000$ children per year. ${ }^{16}$ Yet another retrospective study from Texas states that the prevalence of HLH in their part of the world is at least 1 in 100,000 persons below 18 years. ${ }^{17}$

Hyperferritinemia is considered as both diagnostic and prognostic marker in HLH. ${ }^{18}$ Ferritin level estimation is a rapid and very useful test done in almost all the centers. Serum ferritin level $>10,000 \mathrm{microgram} / \mathrm{dl}$ was considered to have a sensitivity of $>90 \%$ and a specificity of $>96 \%$ in cases of HLH..$^{15,19}$ All our patients had a serum ferritin level of $>35000 \mathrm{mcg} / \mathrm{dl}$. In an analysis by Anthony et al, it was found that, among the HLH defining criteria, serum ferritin $>2600 \mathrm{mcg} / \mathrm{dl}$ and platelet value $<100 \times 10^{9} / \mathrm{L}$ were independently associated with HLH diagnosis in adults. ${ }^{20}$ But Schram et al suggested that marked elevation in serum ferritin level does not suggest HLH in adult population unlike in the pediatric population. ${ }^{21}$

There has been no consensus of opinion regarding the number of HPCs in the marrow smears. But it has been suggested that careful search for HPCs should be done in at least three smears with each revealing at least two HPCs. Dyserythropoiesis of cells is a reactive finding in bone marrow described in dengue fever. ${ }^{22}$ Caleb et al in their study indicated that marrow pathology alone is not predictive of the probability of $\mathrm{HLH}^{23}$ They evaluated bone marrow aspirate of 58 cases and found that there was no significant difference in the number of HPCs between HLH high-risk group and HLH low-risk group. But, demonstration of lymphohistiocytic hemophagocytosis in bone marrow helps in an early diagnosis along with other laboratory parameters, even though it is not essential for the diagnosis. ${ }^{24}$

Even though an elevated level of CD25, Interferon gamma, and interleukin-10 have high sensitivity and specificity in differentiating HLH from other infections, the estimation is done only specialized laboratories and is not practical in the resource-poor settings. We have not performed these tests in our patients as they were not available in our institution. Nearly half of our cases had hemorrhagic manifestations. We found a prolonged APT'T value in 10/11 patients. Biochemical evidence of liver injury was present in all the patients.

High mortality associated with HLH is described in many publications. In a retrospective analysis of $103 \mathrm{HLH}$ cases, 77 patients $(74.8 \%)$ succumbed to illness. ${ }^{25}$ Majority of the patients in their study were having malignancy associated HLH. Among those who died, nearly half likely died related to malignancy rather than HLH. In their study, the mortality in case of viral infection associated HLH was $50 \%$. In our study also we experienced high death rate. 8 out of 11 patients did not survive even with medical intervention.

\section{CONCLUSION}

HLH is a medical emergency which can behave in an aggressive manner with high mortality in a very short 
period. Low incidence actually reflects the underdiagnosis of the condition. Even though it is difficult in every center to test the newly included parameters for diagnosis, like NK cell activity and CD25 level, etc., clinical features and laboratory parameters like cytopenia, hyperferritinemia, etc should make the clinician have a high index of suspicion of HLH. Our study underscores the need for physicians to be vigilant about the high mortality nature of this condition. This article is an attempt to stress the importance of timely diagnosis of HLH. A large prospective study is mandatory to put forward definite diagnostic criteria for adult HLH.

\section{REFERENCES}

1. Janka GE and Lehmberg K. Hemophagocyticlymphohistiocytosis: pathogenesis and treatment. Hematology Am Soc Hematol Educ Program 2013;2013:605-611.

2. Farquhar JW and Claireaux AE. Familial haemophago cyticreticulosis.Arch Dis Child 1952;27(136):519-525.

3. Risdall FJ, McKenna RW, Nesbit ME, Krivit W, Balfour HH Jr, Simmons RL, et al. Virus-associated hemophagocytic syndrome. A benign histiocytic proliferation distinct from malignant histiocytosis. Cancer 1979; 44(3):993-1002.

4. Allen CE, YuX, Kozinetz CAand McClai KL. Highly elevated ferritin levels and the diagnosis of hemophagocyticlymphohistiocytosis, Pediatr Blood Cancer 2008; 50(6)1227-1235.

5. Henter JI, Elinder $G$ and Ost A. Diagnostic guidelines for hemophagocyticlymphohistiocytosis. The FHL Study Group of the Histiocyte Society.Semin Oncol 1991; 18(1):29-33.

6. Henter $\mathrm{JI}$, Horne A, Aricó M, Egeler RM, Filipovich AH, Imashuku S, et al. HLH-2004: Diagnostic and therapeutic guidelines for hemophagocyticlymphohistiocytosis. Pediatr Blood Cancer 2007;48:124-131.

7. George MR. Hemophagocyticlymphohistiocytosis: review of etiologies and management. Journal of Blood Medicine 2014;5:69-86.

8. Hoşnut FÖ, Ozçay F, Malbora B,Hızlı $S$ and Ozbek N. Severe adenovirus infection associated with hemophagocyticlymphohistiocytosis. Turkish journal of hematology: official journal of Turkish Society of Haematology 2014;31(1):103-105.

9. SharpTM, Gaul L, Meuhlenbachs A, Hunsperger E, Bhatnagar J and Lueptow R. Fatal hemophagocyticlymphohistiocytosis associated with locally acquired dengue virus infection - New Mexico and Texas, 2012. MMWR Morb Mortal Wkly Rep 2014;63(3):49-54.

10. Ab-Rahman HA, Rahim $H$, AbuBakar $S$ and Wong PF. Macrophage Activation Syndrome-Associated Markers in Severe Dengue. Int J Med Sci 2016;13(3):179-186.
11. Jasmine YS, Lee SL and Kan FK. Infection associated haemophagocytic syndrome in severe dengue infection - a case series in a district hospital. Med J Malaysia 2017;72(1):62-64.

12. Koshy M, Mishra AK, Agrawal B, Kurup AR and Hansdek SG. Dengue fever complicated by hemophagocytosis. Oxf Med Case Reports 2016(6):121-124.

13. Mitra $S$ and Bhattacharyya R. Hemophagocytic syndrome in severe dengue Fever: a rare presentation. Indian J Hematol Blood Transfus 2014;30(1):97-100.

14. Jayashree K, Rao S and Kamath N. Influenza B Virus Triggering Macrophage Activation Syndrome in an Infant. Indian J Crit Care Med 2017;21(11):802-803.

15. Rosado FG and Kim AS. Hemophagocyticlymphohistiocytosis: an update on diagnosis and pathogenesis. Am J Clin Pathol 2013;139(6):713-727.

16. Henter JI, Elinder G, Söder O and OstA. Incidence in Sweden and clinical features of familial hemophagocyticlymphohistiocytosis. Acta Paediatr Scand 1991; 80(4):428-435.

17. Niece JA, Rogers ZR, Ahmad N, Langevin AM and McClain KL. Hemophagocyticlymphohistiocytosis in Texas: observations on ethnicity and race. Pediatr Blood Cancer 2010; 54(3):424-428.

18. Lin, TF, Ferlic-Stark LL, Allen CE, Kozinetz CA and McClain KL. Rate of decline of ferritin in patients with hemophagocyticlymphohistiocytosis as a prognostic variable for mortality. Pediatric Blood and Cancer 2011;56(1):154-155.

19. Chaudhuri SR, Bhattacharya S, Chakraborty $M$ and Bhattacharjee K. Serum Ferritin: A Backstage Weapon in Diagnosis of Dengue Fever. Interdisciplinary Perspectives on Infectious Diseases 2017; 7463489.

20. Pham AQ, O'Byrne MM, Kapoor P, Shah MV, Abraham RS, Go RS, et al. Analysis of serum ferritin levels as diagnostic criteria for hemophagocyticlymphohistiocytosis (HLH) in hospitalized adult patients. Blood 2015;126:1014.

21. Schram AM, Campigotto F, Mullally A, Fogerty A, Massarotti E and Neuberg D. Marked hyperferritinemia does not predict for HLH in the adult population. Blood 2015;125(10):1548-1552.

22. Lu PL, Hsiao HH, Tsai JJ, Chen TC, Feng MC and Chen TP. Dengue virus-associated hemophagocytic syndrome and dyserythropoiesis: a case report. Kaohsiung J Med Sci 2005;21(1):34-39.

23. Ho C, Yao X, Ligeng Tian L, Li F, Podoltsev N and Xu ML. Marrow Assessment for HemophagocyticLymphohistiocytosis Demonstrates Poor Correlation With Disease Probability. Am J Clin Pathol 2014;141(1):62-71.

24. Nair V, Das S, Sharma A, Sharma S, Sharma P, Ray S, et al. A clinicopathological analysis of 26 patients with infectionassociated haemophagocyticlymphohistiocytosis and the importance of bone marrow phagocytosis for the early initiation of immunomodulatory treatment Postgrad Med J 2014;89(1050):185- 192.

25. Li J, Wang Q, Zheng W, Ma J, Zhang W, Wang W, et al. Hemophagocyticlymphohistiocytosis: Clinical analysis of 103 adult patients. Medicine (Baltimore) 2014;93(2):100-105.

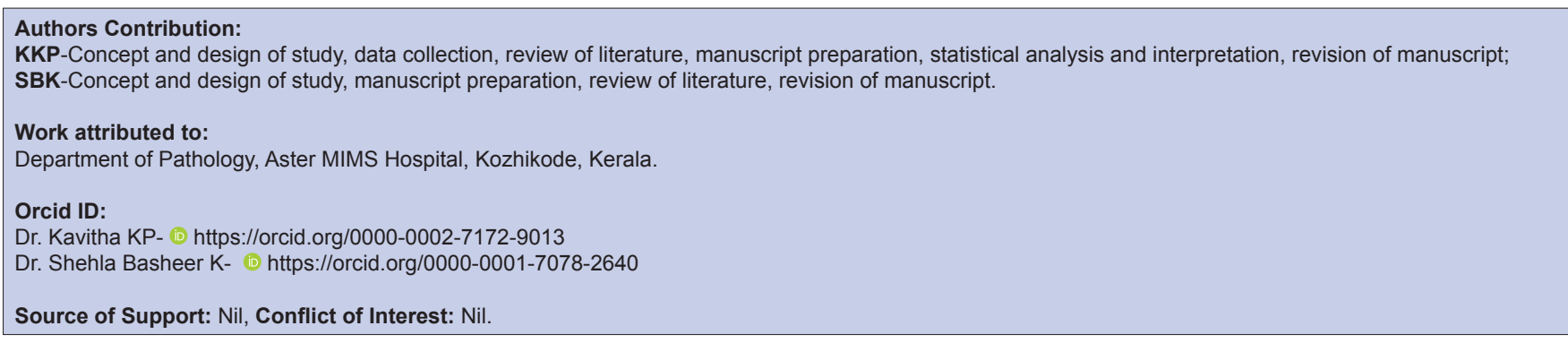

